\title{
EXCISION OF THE COCCYX FOR COCCYDYNIA
}

\author{
A Study of the Results in Twenty-eight Cases
}

\author{
J. B. Pyper, Belfast, Northern Ireland \\ From the Musgrave Park Hospital, Belfast
}

Pain in the region of the coccyx is a condition in which "at present there is wide divergence of opinion concerning the best form of treatment" (Key 1937). In particular, there is no general agreement about the effectiveness of excision of the coccyx in relieving the symptoms. Most surgeons appear to be dissatisfied with the results of this operation. Edwards (1938) stated that there is "more or less continuous disagreement" about the effectiveness or otherwise of operation, and concluded that " because of the frequent failure of excision to effect a cure, conservative measures should be persisted with for longer periods than is generally the practice."

In order to obtain further evidence on this point a study has been made of the results of operation over a ten-year period.

\section{MATERIAL AND METHOD OF STUDY}

Records of the thirty-four patients subjected to excision of the coccyx for coccydynia from 1947-56 were obtained from the Musgrave Park Orthopaedic Hospital, Belfast, and from the Orthopaedic Departments of the Royal Victoria and Belfast City Hospitals. Of these thirty-four patients twenty-one attended for review and seven replied to a postal enquiry. The results of twenty-eight operations were thus available for study.

Each patient was asked to choose from a list of five categories of result (Table I) his own estimate of the effect of the operation upon the coccygeal pain. The patients were also asked whether they had suffered low-back pain with the coccygeal pain, whether they recalled any injury related to the onset of symptoms, how long the symptoms had been present before operation, and how long after operation most benefit was obtained. They were also asked about previous conservative treatment. The available notes of the pre-operative physical and radiographic examination were studied.

TABLE I

Five Categories of Result Submitted for Patient's OWN Assessment of EfFect Of Operation

\begin{tabular}{|c|}
\hline Complete relief \\
Marked improvement \\
Slight improvement \\
No relief \\
Worse than before
\end{tabular}

\section{ANALYSIS OF RESULTS}

The total series of thirty-four patients comprised twenty-nine women and five men, aged from eighteen to sixty (average thirty-five) years. 
The time since operation, in the twenty-eight patients traced, varied from four months to ten years, with an average of three and a half years.

By asking the patients each to select his or her individual result from the alternatives shown in Table I it was expected that the results could be studied in five groups. No patient, however, selected either "slight improvement" or "worse than before" as the appropriate description. The results, therefore, fall into three groups and the number of patients in each group is shown in Table II.

In the twenty-five patients comprising groups 1 and 2 fullest relief of symptoms was experienced at a period after operation which varied from six weeks to eighteen months (average $4 \cdot 2$ months).

In an attempt to determine whether there was any significant correlation between the various factors involved (Table III) and the result of operation, several possible determinants were studied.

TABLE II

Analysis of Results (Twenty-eight Cases)

\begin{tabular}{|c|c|c|c|}
\hline Group & Result & Number & Per cent \\
\hline 1 & Complete relief & 13 & 46 \\
\hline 2 & Marked improvement & 12 & 43 \\
\hline \multirow[t]{2}{*}{3} & No relief. & 3 & 11 \\
\hline & Total . & 28 & 100 \\
\hline
\end{tabular}

TABLE III

INCIDENCE OF RELEVANT FACTORS

\begin{tabular}{|c|c|c|c|}
\hline & Group 1 & Group 2 & Group 3 \\
\hline History of injury . & $46 \%$ & $50 \%$ & $66 \%$ \\
\hline Lumbar backache . & $46 \%$ & $50 \%$ & $33 \%$ \\
\hline Conservative treatment tried & $31 \%$ & $33 \%$ & $33 \%$ \\
\hline $\begin{array}{l}\text { Average duration of symptoms, } \\
\text { in months, before operation }\end{array}$ & 25 & 29 & 67 \\
\hline
\end{tabular}

History of injury-A definite history of injury in association with the onset of symptoms was described by six of the thirteen patients in group 1, six of the twelve patients in group 2, and two of the three patients in group 3. In most cases this injury was external-a fall on the seat or a direct blow over the coccyx. One patient in group 1 and one patient in group 2 blamed a difficult confinement for the onset of the complaint.

Associated lumbar pain-Lumbar pain was present with coccydynia before operation in six patients in each of groups 1 and 2 and one patient in group 3. In no case did removal of the coccyx relieve the lumbar backache, and in three cases lumbar aching was experienced for the first time after the operation.

Failed conservative treatment-Conservative treatment, mainly by manipulation and injection of local analgesics, but also including various forms of physiotherapy, had been tried without success in almost a third of the patients operated upon, and in about the same proportion in each group. 
Duration of symptoms before operation-This varied from four months to ten years and tended to be longer in the less successful groups.

Tenderness-In all patients the coccyx was reported to be tender on rectal examination either on pressure or on movement.

Radiographic changes-Many variations were noted in the patients who were radiographed before operation. In some the coccyx appeared as a single bone; in others three or more segments were visible. In some there was irregularity of the sacro-coccygeal joint. The coccyx was acutely anteflexed in four; in only one case was it considered to have been broken. The numbers showing any one of these variations were insufficient to allow any reliable conclusions to be drawn.

Other factors-For the whole group the average time spent in hospital after operation was three weeks. Only one patient developed any complication: this was a persistent sinus in the region of the wound which was cured, four months after operation, by curettage of the wound, removal of non-absorbable buried sutures, and re-suture. The result in this case fell into group 2.

TABLE IV

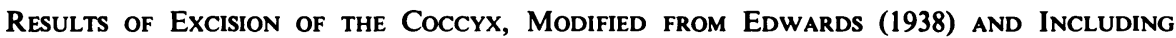
Present Figures for Comparison

\begin{tabular}{|c|c|c|c|c|c|c|}
\hline Author & Cases & Traced & Cured & Improved & Unimproved & $\begin{array}{c}\text { Per cent } \\
\text { unimproved }\end{array}$ \\
\hline Duncan & 30 & 30 & 22 & 3 & 5 & 17 \\
\hline Hansa & 49 & 49 & 40 & 0 & 9 & $18 \cdot 4$ \\
\hline Key . & 15 & 14 & 12 & 2 & $\mathbf{0}$ & 0 \\
\hline \multirow[t]{2}{*}{ Edwards } & 37 & 16 & 8 & 6 & 2 & $12 \cdot 5$ \\
\hline & & & & & Average: & $11 \cdot 9$ \\
\hline Present series & 34 & 28 & 13 & 12 & 3 & $10 \cdot 7$ \\
\hline
\end{tabular}

\section{DISCUSSION}

Coccydynia is a subjective complaint, and it is reasonable therefore to assess the results of treatment on a subjective basis; indeed this seems to be the only possible method. Not only is it necessary to depend on the patients' assessment of the results of operation, one is similarly limited in deciding, in the first place, that operation is indicated. This study suggests that there is no constant factor in the history, no reliable physical sign, and no specific radiographic change that can be regarded as a definite pointer in advising operation. If we consider the results simply in two groups, " improved " and " unimproved," the latter contains such a small number (three) of patients that percentages are meaningless. On the other hand there is no one factor present in more than 50 per cent of the improved group. That is to say neither injury nor the lack of it, nor the previous use of conservative treatment, nor the presence (or absence) of lumbar backache is a preponderant factor among patients treated successfully by operation. That the length of history is longer in the least successful group is because this very small group happens to include one patient with a ten-year history. These conclusions agree fairly closely with the experience of previous observers.

Edwards (1938) placed no reliance on the exact site of pain or tenderness, on fixity or mobility of the coccyx, or on its radiographic appearance. Moreover he quoted Duncan who made a radiological study of 200 patients and could not demonstrate any constant difference 
between normal and painful coccyges. Nor could Key (1937) find any correlation between radiographic appearance and the later operative result. From these reports it appears to be agreed that it is impossible to select patients for operation on the basis of events in the history or findings on examination, although Key considered failure of conservative treatment an indication for operation. The authors differ, however, in their conclusions regarding the effectiveness of operation. Key, claiming improvement in all of fourteen cases, concluded that " excision and careful restoration of the pelvic floor may be expected to relieve symptoms and cause no disability." He maintained that good results depend not so much on any method of selection of patients as on meticulous operative technique. Edwards reported two failures out of sixteen operations, and regarded this failure rate as a strong argument for persisting with conservative measures. As well as his own figures and those of Key, already mentioned, he quoted the results of Hansa and of Duncan (Table IV). Nixon (1939) declared that operation gave good results in 85 per cent of patients as compared with 62 per cent of good results in patients treated conservatively.

The results tabled by Edwards were expressed as "per cent of patients unimproved." The average in this category for the four sets of figures quoted was 11.9. The corresponding figure in the present series is $10 \cdot 7$-a very close parallel.

My own observations agree with those of previous authors, except that failure of conservative treatment does not appear to be a pre-requisite in recommending operation as this factor was present in only 32 per cent of the "cured or improved "group in my series.

The difference of opinion regarding the effectiveness of operation appears to lie not so much in the actual figures as in their interpretation. But if we accept a rate of 11 per cent as the average number of patients unimproved after operation this implies a worthwhile result in almost 90 per cent-surely a very satisfactory figure.

One other interesting point emerges. Of the three patients who gained no relief from operation two had, at the time of review, been referred for a psychiatric opinion because of numerous widespread aches and pains without demonstrable organic basis. The report on one of these patients was that she was "suffering from a severe neurotic depression with marked suicidal tendencies." The third patient, though not seen by a psychiatrist, was regarded by an independent observer as " grossly hypochondriacal with a great tendency to exaggerate her symptoms." Were it possible to exclude this type of patient I believe the figure of 90 per cent " cured or improved" could be bettered. As it is, the present study suggests that the number of "psychoneurotic coccydynias" that reach the operating table is small, and it seems clear that " the functional and psychological aspect of coccydynia has been exaggerated " (Watson-Jones 1943).

Finally it should be made clear that this review is not intended to be a comprehensive study of coccydynia or of the various forms of treatment that have been used in this condition. It merely sets out to answer the specific question: " is coccygectomy any good?" Judging from the enthusiastic and grateful replies received from many patients, and from the fact that almost 90 per cent of them have gained worthwhile benefit from the operation, it seems clear that the question can be answered in the affirmative.

\section{SUMMARY}

1. Twenty-eight patients subjected to excision of the coccyx for coccygeal pain during the last ten years have been reviewed.

2. No constant means of selection appears to have been used in recommending these patients for operation, and, in retrospect, no factor in the history or examination emerges as reliable for making such selection in the future.

3. Operation may be recommended as likely to provide a cure in about 45 per cent and to give worthwhile relief in another 45 per cent of cases. 
4. When conservative treatment has succeeded, operation will not, of course, be required, but failure of conservative treatment is not an essential pre-requisite in recommending operation. 5. If more care were taken to eliminate the markedly psychoneurotic patients the worthwhile results of operation could probably be increased even above 90 per cent.

6. Excision of the coccyx is certainly a useful operation and should not be discarded.

I should like to thank all the surgeons in charge of the departments concerned for permission to study their patients, and the nursing and clerical staff, particularly the clerical staff of Musgrave Park Hospital, for valuable assistance.

\section{REFERENCES}

Edwards, M. (1938): Trauma of the Coccyx and Coccygodynia. American Journal of Surgery, N.S. 42, 591. KeY, J. A. (1937): Operative Treatment of Coccygodynia. Journal of Bone and Joint Surgery, 19, 759.

Nixon, E. A. (1939): Coccygodynia. American Journal of Surgery, N.S. 44, 390.

Watson-Jones, Sir R. (1943): Fractures and Joint Injuries. Third edition. Vol. 1, p. 382. Edinburgh: E. \& S. Livingstone Ltd. 